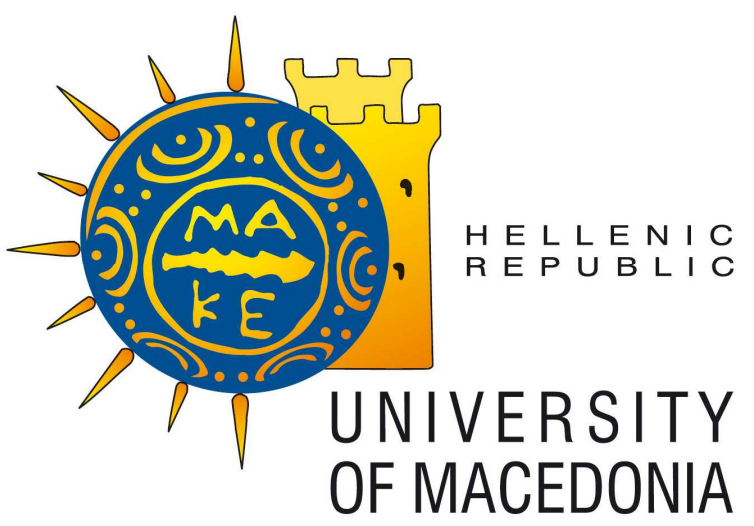

ISSN 1791-3144

\author{
University of Macedonia \\ Department of Economics
}

Discussion Paper Series

\title{
Effectiveness of Government Policies in Response to the COVID-19 Outbreak
}

Theologos Dergiades, Costas Milas, Elias Mossialos and Theodore Panagiotidis

\section{Discussion Paper No. 5/2021}

Department of Economics, University of Macedonia, 156 Egnatia str, 54636 Thessaloniki, Greece, Fax: + 30 (0) 2310891292

http://www.uom.gr/index.php?newlang=eng\&tmima=3\&categorymenu=2 


\title{
Effectiveness of Government Policies in Response to the COVID-19 Outbreak
}

\author{
Theologos Dergiades \\ Department of International \\ \& European Studies \\ University of Macedonia, Greece \\ e-mail: dergiades@uom.edu.gr
}

\author{
Costas Milas* \\ Management School \\ University of Liverpool, \\ United Kingdom \\ e-mail: costas.milas@liverpool.ac.uk
}

\begin{abstract}
This paper assesses the quantitative impact of government interventions on deaths related to the COVID-19 outbreak. Using daily data for 32 countries and relying on the stringency of the conducted policies, we find that the greater the strength of government interventions at an early stage, the more effective these are in slowing down or reversing the growth rate of deaths. School closures have a significant impact on reducing the growth rate of deaths, which is less powerful compared to the case where a number of policy interventions are combined together. These results can be informative for governments in responding to future COVID-19 outbreaks or to other pandemics not least because there is a possibility of further waves of COVID-19 infections and deaths as governments progressively relax their interventions.
\end{abstract}

Keywords: COVID-19; OxCGRT index; Effectiveness of Government Responses; Excess Mortality.

JEL: C1; C5; I1

\footnotetext{
* Corresponding author: Costas Milas, Management School, University of Liverpool, Chatham Street, L69 7ZH, Liverpool, UK. E-mail: costas.milas@liverpool.ac.uk.

We thank Michael Ellington for providing comments on an earlier version of the paper. We have discussed the results of the paper in an opinion piece for the London School of Economics and Political Science British Politics blog (https://blogs.lse.ac.uk/politicsandpolicy/covid19-interventions-death-rate/). The Financial Times acknowledges our use of their excess mortality data at: https://github.com/Financial-Times/coronavirus-excessmortality-data.
} 


\section{Introduction}

As evident by the tremendous media attention, the COVID-19 pandemic has triggered severe social and economic costs. The Financial Times, for instance, has a dedicated website ${ }^{1}$ which provides free access to its analysis. At the time of writing, there were around 25.5 million confirmed cases of COVID-19 infections and 0.85 million deaths. ${ }^{2}$ Lessons learned from previous pandemics imply a huge impact on economic activity. Barro et al. (2020) use data for 43 countries to find that the 'Spanish flu' of the 1918-1920 period generated real per capita GDP declines of $6 \%$ for countries on average. Using data stretching back to the 14 th century for France, Germany, Italy, the Netherlands, Spain, and the UK, Jordà et al. (2020) show that pandemics depress the real rate of interest for years after a pandemic, perhaps as many as 40 years (wars do not have such effects).

To bring down COVID-19-related infections and deaths in the pandemic thus far, governments have responded with a number of interventions. Among others, Cowling et al. (2020) show that non-pharmaceutical interventions (including border restrictions, quarantine and isolation, distancing, and changes in population behavior) were associated with reduced transmission of COVID-19 in Hong Kong. Using data for Germany, Hartl et al. (2020a, b) find a reduction in the growth rate of COVID-19, seven days after the implementation of containment policies on 13 March 2020 and again eight days after the implementation of further measures on 22 March 2020. Chen and Qiu (2020) rely on a dynamic panel epidemiological model of nine countries to show that interventions like mask wearing and centralized quarantine can replace the costly, in economic terms, national lockdown without significantly heightening the epidemic peak. Basu et al. (2020) use panel data analysis for the case of England to find that greater stringency is associated with stronger social distancing; nevertheless, the poor still distance less than the rich. Hsiang et al. (2020) use panel regression analysis to find that interventions prevented or delayed around 530 million COVID-19 infections across six countries (China, South Korea, Iran, Italy, France, and the United States). Chudik et al. (2020) rely on an epidemiological model for a number of Chinese provinces and ten countries to find that it takes about 21 days from infection to recovery (or death) rather than the 14 days typically assumed in designing quarantine policies.

\footnotetext{
${ }^{1}$ See: https://www.ft.com/coronavirusfree.

2 See: https://www.ecdc.europa.eu/en/geographical-distribution-2019-ncov-cases.
} 
As the first wave of the COVID-19 outbreak appears to be easing in many countries around the globe, it is extremely crucial to provide an initial quantitative assessment of the impact that ongoing government interventions have had on controlling the pandemic. As noted by a recent communication news article in Nature (Gibney, 2020), "working out the effectiveness of the measures implemented worldwide to limit the coronavirus's spread is now one of scientists' most pressing questions". The pressing issue of the efficacy of government interventions could be further addressed by the following questions: First, can a prompt and strict government response curb the mortality curve of the epidemic? Second, does the severity of interventions affect (and by how much) the subsequent evolution of the growth rate of deaths? Third, under uncontrolled pandemic conditions, can the shift to harsher measures lower (and by how much) the growth rate of deaths? Providing this information should be vital to governments as they attempt to design strategies to return to a 'new normal' and, at the same time, prevent further waves of the COVID-19 outbreak.

This paper attempts to address these critical questions in a quantitative manner. To do so, we first define two critical concepts: (i) the strength of the policies and (ii) the early stage implementation of these policies. In particular, we define the policy strength of any certain day as the average value of the Government Response Tracker index (developed by the University of Oxford) for the preceding 14 days (Lauer et al. 2020, estimate that the incubation period of the virus is 14 days). Early stage refers to any day that precedes or is equal to the first observed day in which the number of confirmed deaths is at least five (both definitions are further discussed in section 5). Considering these concepts, we form three hypotheses of interest. "Speed is of the essence" is our first hypothesis. That is, if COVID-19 policy measures are effective, then the strength of these measures taken at an early stage should be related positively to the probability of attaining a statistically insignificant trend in deaths attributable to COVID-19. "Stringency matters" is our second hypothesis. Upon realization of a positive significant trend in deaths, and under the assumption that the COVID-19 related policy measures taken at an early stage have been effective, then the strength of these measures should still inversely affect the trend slope shaped by the COVID-19 deaths. "Speed of adjustment matters" is our third hypothesis. As countries that initially responded with "low strength" policy measures progressively increase the strength of their response, a significant reduction in the trend slope should take place after a certain breakpoint in time. Thus, for countries with a break in the trend slope, if COVID-19 policy measures are effective then the difference in the 
strength of the policy measures (between the break time and the early stage) should be related inversely to the difference of the slopes in the observed trends (after and before the break).

To examine these hypotheses, we use daily data on COVID-19 related deaths for 32 countries. We rely on the Perron and Yabu (2009a) statistical test to endogenously determine a break on the linear trend of the logarithm of deaths per country. We also estimate the slope of this trend based on the work of Perron and Yabu (2009b). We then assess the impact of government interventions on the trend slope shaped by the daily number of deaths. Our results suggest that a unit increase in the strength of the overall policy measures (school closures) at an early stage raises the probability of attaining an insignificant trend in deaths by $1.1 \%(0.7 \%)$. We also find that a unit increase in the overall policy measures (school closures) at an early stage lowers the growth rate of deaths by $0.2 \%(0.1 \%)$. Finally, governments that initially respond with "low strength" policy measures but progressively increase the strength of their response, succeed in slowing down or reversing the growth rate of deaths after a certain breakpoint in time. In particular, a unit increase in the adjustment of the overall policy (school closures) between the breakpoint in time and the early stage lowers the difference in the growth rate of deaths (observed after and before the breakpoint) by $0.3 \%(0.1 \%)$. Therefore, we find that the greater the strength of government interventions at an early stage, the more effective these are in slowing down or reversing the growth rate of deaths. Additionally, the evidence suggests that school closures alone, have a significant impact - albeit, one which is less powerful in reducing the growth rate of deaths than that achieved by pooling together a number of government interventions. Overall, governments can use some of the results of this paper to respond to future COVID-19 outbreaks or to other pandemics not least because further waves of COVID-19 infections and deaths are likely to emerge as policymakers progressively relax their interventions; indeed, August 2020 saw a further rise in confirmed COVID-19 cases. $^{4}$

The paper proceeds as follows: section 2 discusses the data; section 3 provides the theoretical motivation; section 4 describes the methodology; section 5 presents the empirical strategy and model estimates; section 6 presents robustness checks and, section 7 concludes.

\footnotetext{
3 Unkel et al. (2012) note that statistical techniques including regression analysis, Bayesian and Hidden Markov models and methods incorporating spatial information have been used in the literature to identify a prospective detection of outbreak of infection diseases.

4 See e.g. https://www.theguardian.com/world/2020/aug/17/global-report-alarm-over-covid-case-rates-19european-countries.
} 


\section{Data}

We focus on 32 countries that have been affected by the pandemic crisis and use daily data on the total number of confirmed deaths attributed to COVID-19. Our sample covers the January $1^{\text {st }}, 2020$ to April $30^{\text {th }}, 2020$ period. The accuracy of official confirmed cases of COVID-19related infections is limited by how effectively a country is testing people to confirm cases and accurately reporting results. For example, Germany and South Korea have been much more aggressive in testing and confirming infections than other countries. ${ }^{5,6}$ With this in mind, we focus on deaths related to COVID-19. The raw data on the daily deaths for all countries of our sample come from the European Centre for Disease Prevention and Control (ECDC). ${ }^{7,8}$

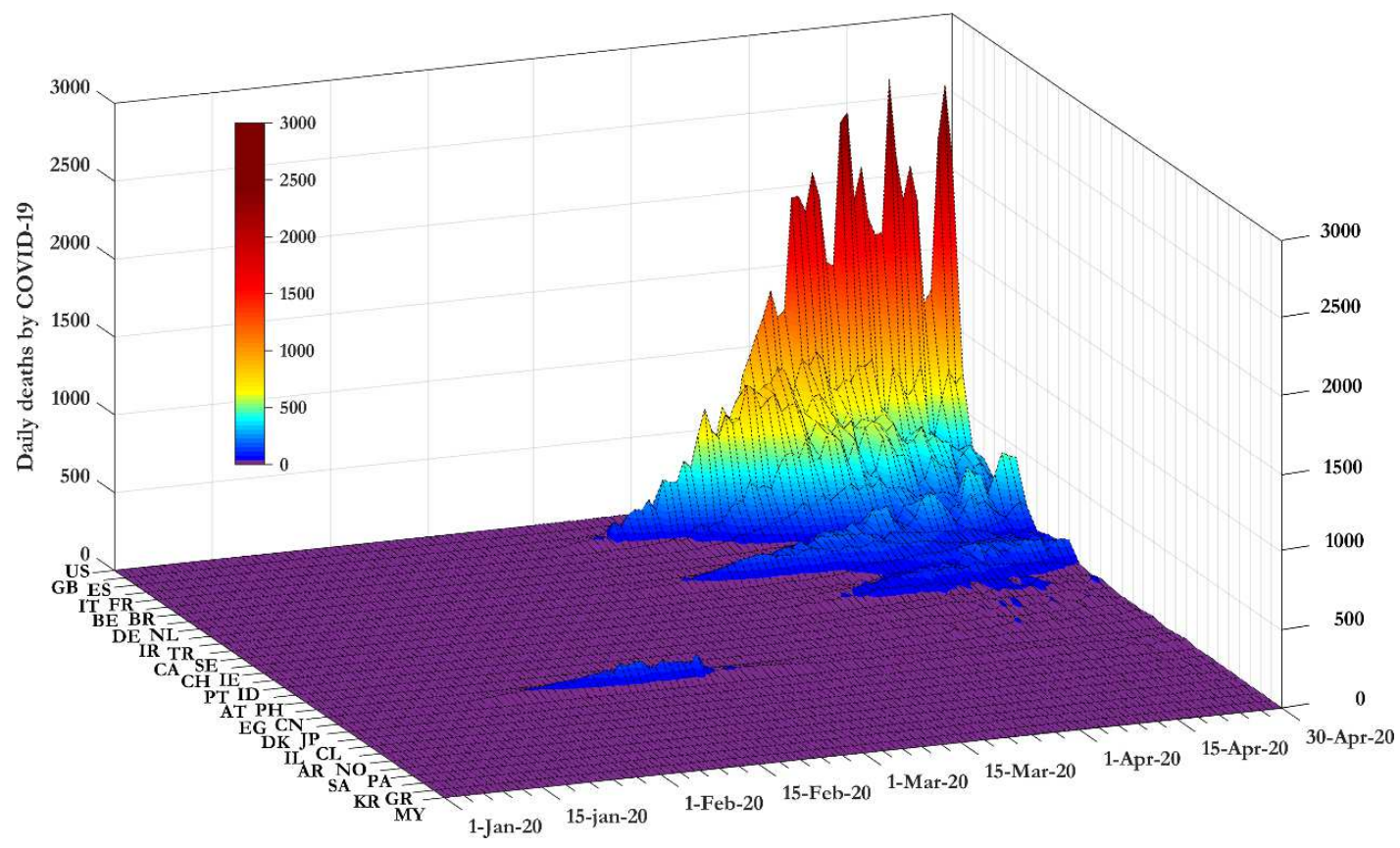

Figure 1. Confirmed deaths attributed to COVID-19 across countries.

\footnotetext{
5 See: https://cutt.ly/Bylfgv2

${ }^{6}$ Manski and Molinari (2020) note the problem with missing data on confirmed cases of COVID-19 and rely on partial identification techniques to estimate infection rate bounds for two states in the United States (Illinois and New York) and Italy.

7 Available at: https://cutt.ly/pyqHIRZ. For the case of France, due to the late and at the same time cumulative report of deaths from retirement homes and assisted living facilities we use the officially reported deaths in hospitals (available at https://dashboard.covid19.data.gouv.fr/). Similarly, for the case of China, we ignore the late and cumulative reported number of deaths that took place in late April.

8 The sample countries along with their ISO alpha-2 codes are: Argentina (AR), Austria (AT), Belgium (BE), Brazil (BR), Canada (CA), Chile (CL), China (CN), Denmark (DK), Egypt (EG), France(FR), Germany (DE), Greece (GR), Indonesia (ID), Iran (IR), Ireland (IE), Israel (IL), Italy (IT), Japan (JP), South Korea (KR), Malaysia (MY), the Netherlands (NL), Norway (NO), Panama (PA), Philippines (PH), Portugal (P'T), Saudi Arabia (SA), Spain (ES), Sweden (SE), Switzerland (CH), Turkey (TR), United Kingdom (GB) and United States (US).
} 
Figure 1 reports the data in levels. We present that data in levels as Romano et al. (2020) show that when COVID-19 related data are presented in a linear scale (compared to the log scale) eases the public to understand better the underlying information, improving this the level of worry about the pandemic or even to affect public policy preferences. From Figure 1, daily deaths in China reached a peak in mid-February before dropping again (isolated blue surface in the purple area). Daily deaths in Italy reached a peak in late March 2020. Daily deaths in Spain, France and the UK reached a peak in early April 2020.

Deaths due to COVID-19 forced governments to implement a range of policies to control the spread of the virus. The Blavatnik School of Government of the University of Oxford compiles the Oxford COVID-19 Government Response Tracker (OxCGRT) index (see Hale et al., 2020) which quantifies the stringency of the conducted policies across countries. The value of the index on any given day in any given and country comes from the average of nine sub-indices ${ }^{9}$ pertaining to individual policy indicators, each taking a value between 0 and 100 (for a detailed definition of the index see Hale et al., 2020). The raw data ${ }^{10}$ of the index for the sample countries is shown in Figure 2.

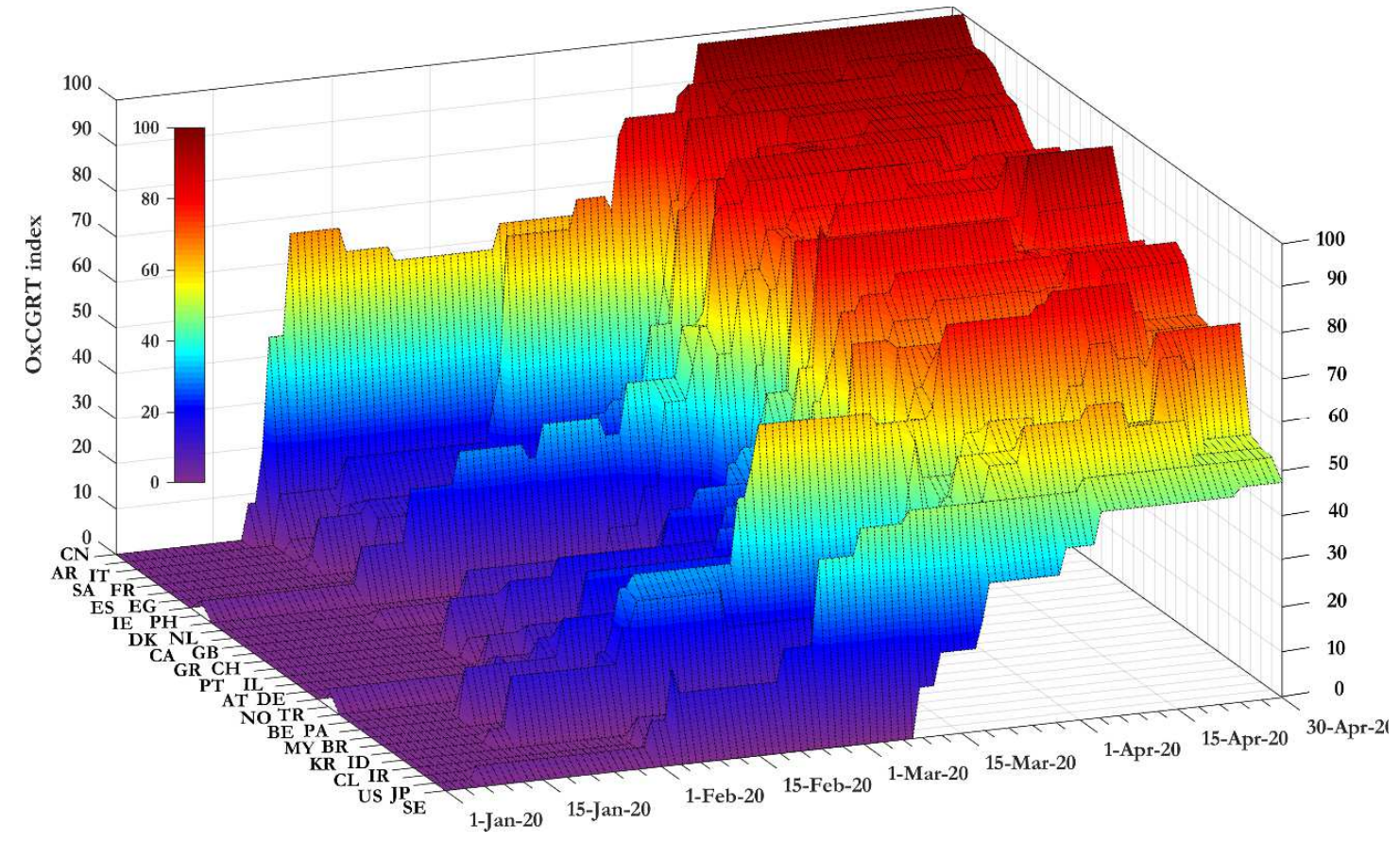

Figure 2. The OxCGRT index across countries

\footnotetext{
9 These are: school closures, workplace closures, cancelation of public events, restrictions on gathering size, closure of public transport, stay at home requirements, restrictions on internal movement, restrictions on international travel, and public information campaign.

10 Available at: https://cutt.ly/mylfYBc.
} 
From Figure 2, stringency measures in China increase steeply in late January 2020. Among other countries, stringency measures in Italy increase significantly in late February 2020. Then follow Spain and France, the UK and the US. ${ }^{11}$

\section{Theoretical motivation}

The rationale for the structure of the estimated specifications in Section 5 can be deployed by linking the framework of a reduced-form econometric model, commonly implemented in economics to assess the impact of various conducted policies on target variables, and a typical epidemiological model. The use of reduced-form econometric specifications in epidemiology is not new. These specifications may prove quite informative when the purpose of the analysis is not to describe the mechanism of disease transmission, but rather to evaluate the impact of disease-related interventions on the number of cases or deaths (Hsiang et al. 2020). The main advantage of reduced-form econometric modeling is that it permits sufficient inference on the total effectiveness of policy interventions without the need to provide input for essential epidemiological parameters that may be uncertain or even unknown.

Along the same lines, Hsiang et al. (2020) rely on a typical Susceptible-InfectedRecovered (SIR) model to focus on the initial phase of the outbreak where the susceptible individuals in the limit approximate the population and the infections increase exponentially. Hsiang et al. (2020) show that the initial system of equations is reduced to a simple first-order differential equation, which describes the change of infections in the beginning of the outbreak. The general solution for the number of infections at time $t(I(t))$ is:

$$
I(t)=I(0) e^{g t},
$$

where $I(0)$ is the number of infections at the start of the process, $e$ is the Naperian base and $g$ is the growth rate of infections at each unit of time.

By calculating the natural logarithm for the ratio of the general solution over two sequential points in time (e.g. $t_{2}$ and $t_{1}$ ), it is easily shown that the growth rate of infections is equal to the difference of two principal parameters of the SIR model:

$$
\log \left(I\left(t_{2}\right)-\log \left(I\left(t_{1}\right)\right)=g=\beta-\lambda,\right.
$$

\footnotetext{
${ }^{11}$ Notice that the left horizontal axes in Figures 1 and 2 report the sample countries in a different order. We do this on purpose to optimize the information content communicated by each Figure.
} 
where $\beta$ is the transmission rate of the disease and $\lambda$ is the recovery rate. In the absence of vaccination and other government interventions (e.g. social distancing measures which affect $\beta$ or health system investments that affect $\lambda$ ), the growth rate remains time-invariant. Under the realistic hypothesis that the very short-run investments on the health system do not alter $\lambda$, the growth rate of infections becomes time-dependent only when disease anti-contagion policies are implemented to the susceptible population. In other words, the growth rate of infections may be expressed as a function of the time-varying anti-contagion policies. Assuming a typical linear functional form, the growth rate of infections can be described by the following reduced form econometric specification:

$$
\Delta \log (I(t))=\phi_{0}+\phi_{1} P(t)+u(t),
$$

where $\phi_{0}$ is the growth rate of infections in the absence of social distancing policies, $\phi_{1}$ is the expected impact of these policies on the growth rate of infections, $P(t)$ is a measure of stringency for the conducted social distancing policies at time $t$ and $u(t)$ is a normally distributed stochastic process with constant mean and constant variance.

Equation (3) describes the infection process for a disease and reveals that social distancing policies have a contemporaneous effect on the growth rate of the process. An emerging issue is whether the same process can be applied to model the growth rate of the resulting deaths. As there is a time distance between infection and death, the number of deaths at time $t(D(t))$ is proportional to the number of infections at an earlier time $t-h$. Hence, following Amaro et al. (2020), the number of deaths at time $t$ can be defined as:

$$
D(t)=\xi I(t-h),
$$

where $\xi$ is the proportion of the infected individuals that finally die from the disease and $h$ is the time horizon that separates infection from death. Given equation (4), it can be shown that the growth rate of deaths at time $t$ is equal to the growth of infections at time $t-h$ :

$$
\Delta \log (D(t))=\Delta \log (I(t-h)) .
$$

In the presence of social distancing policies, equations (3) and (5) indicate that these may affect the growth rate of infections instantly (through the transmission parameter $\beta$ ), and impact the growth of deaths only after $h$ time horizons. Thus, the reduced form econometric specification is:

$$
\Delta \log (D(t))=\rho_{0}+\rho_{1} P(t-h)+z(t),
$$


where $\rho_{0}$ is the growth rate of deaths in the absence of anti-contagion policies, $\rho_{1}$ is the average impact of the anti-contagion policies on the growth of deaths and $z(t)$ is the error term. Equation (6) signals that the growth rate of deaths at time $t$ depends on the anticontagion policies implemented $h$ time horizons in the past. As such, econometric specifications which ignore this structure can lead to misleading inferences.

\section{Methodology}

Epidemic curves consist of time-series observations showing the number of cases or deaths. The epidemiological stylized facts along with the respective theoretical underpinnings suggest that the level of an epidemic curve increases exponentially with time, while the log-level of the curve is approximately a linear function of time (Ma, 2020). Hence, since our focus is on the log-level of deaths, the linear testing frameworks of Perron and Yabu $(2009$ a,b) come as a natural choice. In particular, Perron and Yabu (2009a) test for a break in the slope of a trend function of a series without prior information on whether the noise component is integrated of order one or a stationary process. For an autoregressive error component of order one, we assume the following data-generated process for the variable $y_{t}:{ }^{12}$

$$
y_{t}=\mathbf{x}_{t}^{\prime} \mathbf{w}+u_{t} \text {, and } u_{t}=a u_{t-1}+e_{t},
$$

where $t=1, \ldots, T, e_{t}$ is an i.i.d. process with zero mean and variance $\sigma^{2}$, and $\mathbf{x}_{t}$ and $\mathbf{w}$ are $(r \times 1)$ vectors containing the deterministic components of the series depending on the adopted specification and the unknown parameters, respectively. It is also assumed that $u_{0}$ is a finite scalar with $a$ being in the range of $(-1,1]$, allowing this way the error component to be either stationary or integrated of order one. For our purpose, the specification of interest is model II (break in the trend) in Perron and Yabu (2009a). Therefore, $\mathbf{x}_{t}=\left(1, t, D T_{t}\right)^{\prime}, t$ is a simple time trend, $D T_{t}=\mathrm{I}\left(t>T_{1}\right)\left(t-T_{1}\right)$ (where $T_{1}=\left[k_{1} T\right]$ is the break date at some $k_{1} \in(0,1)$ and $\mathrm{I}($.$) is an inidcator function) and \mathbf{w}=\left(b_{0}, b_{1}, b_{2}\right)^{\prime}$. Hence, we focus our interest on testing the hypothesis $\mathbf{R w}=\mathbf{g}$ where $\mathbf{R}$ is a full rank matrix and $\mathbf{g}$ is a $(q \times 1)$ vector of $q$ restrictions; in this case, we focus on the significance of the $b_{2}$ coefficient.

\footnotetext{
12 The extension for higher autoregressive structures of the error component is analytically discussed in Perron and Yabu (2009a).
} 
When $a=1$, its approximation through OLS and the use of quasi-feasible generalized least squares (FGLS) to obtain estimates for $\mathbf{w}$ leads to a Wald statistic $W_{F}\left(k_{1}\right)$ that no longer has a chi-square limit distribution. Hence, Perron and Yabu (2009a) propose a superconsistent estimate of $a$ through the following truncation:

$$
\hat{a}_{M S}=\left\{\begin{array}{cl}
\hat{a}_{M} & \text { if }\left|\hat{a}_{M}-1\right|>T^{-0.5} \\
1 & \text { if }\left|\hat{a}_{M}-1\right| \leq T^{-0.5}
\end{array}\right\},
$$

where $\hat{a}_{M}=\hat{a}+C(\hat{\tau}) \hat{\sigma}_{a}$ with $\hat{a}$ and $\hat{\sigma}_{a}$ the OLS estimate and the respective standard error and $C(\hat{\tau})$ an indicator function of the $\hat{\tau}$ ratio. In this case, $\hat{a}_{M}$ is the Roy and Fuller (2001) coefficient correction for the biased estimate of $\hat{a}$ through OLS. For the case of a known break date, Perron and Yabu (2009a) show that the Wald statistic $W_{F M S}\left(k_{1}\right)$ based on the FGLS with $\hat{a}_{M S}$ has a chi-square distribution irrespective of stationarity issues.

For the case of an unknown break, Perron and Yabu (2009a) propose the following Exp- $W_{F M S}$ statistic estimated for all permissible break dates:

$$
\text { Exp- } W_{F M S}=\log \left[T^{-1} \sum_{K} \exp \left(0.5 * W_{F M S}\left(k_{1}^{\prime}\right)\right)\right],
$$

where $K=\left(k_{1}^{\prime} ; \varepsilon \leq k_{1}^{\prime} \leq 1-\varepsilon\right)$ for $\varepsilon>0$ with $k_{1}^{\prime}$ being the break fraction in the sample and $\varepsilon$ a trimming parameter. The problem with the limit distribution of $\operatorname{Exp}-W_{F M S}$ statistic is that it differs for the cases of an integrated of order one or a stationary process. Consequently, Perron and Yabu (2009a) identify the limit distributions and provide asymptotic critical values for different levels of the trimming parameter $\varepsilon$. Although the limit distributions are different for the two cases above, the critical values for the respective quantiles are quite similar. Hence, Perron and Yabu (2009a) propose to use the larger critical value.

Once the break in trend is identified, Perron and Yabu (2009b) propose an approach to estimate and test the significance of the linear trend in a series $y_{t}$. The approach is again robust to the presence of an integrated or stationary error component. In particular, assuming that in equation (7) the $\mathbf{x}_{t}$ vector reduces to $\mathbf{x}_{t}=(1, t)^{\prime}$ (in which case $\mathbf{w}$ is a $2 \times 1$ vector), the recommended procedure by Perron and Yabu (2009b) is as follows: (i) obtain the OLS residuals $\hat{u}_{t}$, (ii) find the Weighted Symmetric Least-Squares estimate $\hat{a}_{W}$ for the autoregressive parameter $a$ as described in Roy and Fuller (2001), (iii) find the value of $\hat{a}_{M}$ 
by $\hat{a}_{M}=\hat{a}_{W}+C\left(\hat{\tau}_{W}\right) \hat{\sigma}_{a}$ (set $\tau_{p c t}$ to -1.96 ; see Perron and Yabu; 2009b), (iv) calculate the trancated estimate $\hat{a}_{M S}$ based on equation (8) and finally, (v) apply, using $\hat{a}_{M S}$, the GLS approach to get the estimate for the slope coefficient $\hat{b}_{1}$. The significance of $\hat{b}_{1}$ is assessed by the resulting standard t-statisitc. Overall, both approaches of Perron and Yabu (2009a,b) are robust to heteroskedastic errors. Thus, their application, may assist in reducing the effects of error in the measurement of data.

\section{Empirical strategy and findings}

To assess the overall effectiveness of the conducted policies in response to the COVID-19 outbreak, we follow the empirical strategy deployed in Figure 3 below. As the presence of an unknown structural change severely affects the estimation of the slope on the trend component in a series, we begin our analysis by testing for a trend break based on the Perron and Yabu (2009a) methodological framework.

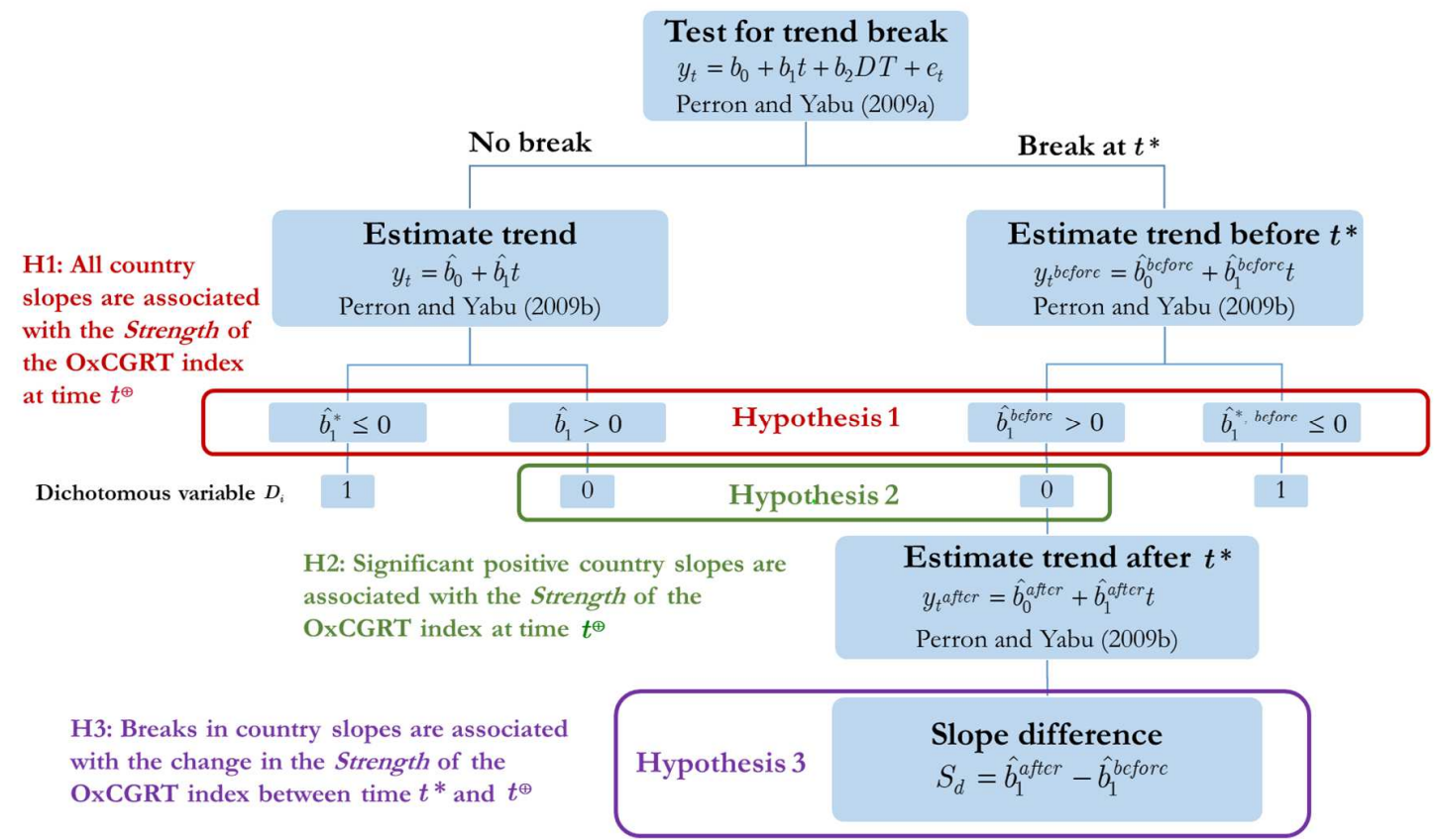

Figure 3. Empirical strategy for investigating the Hypothesis 1, 2 and 3

Starting from the entire data sample $T$ (1 January 2020 to 30 April 2020), we define for each country $i(i=1, \ldots, 32)$ the Effective Testing Sample $\left(E T S_{i}\right)$ as the period marked by the 
first day $\left(t^{\oplus}\right)$ in which the number of confirmed deaths is greater or equal to 5 , up to the end of the sample $T$; that is $\left[t^{\oplus}, T\right] .^{13}$ Hence, based on the $E T S_{i}$ and the logarithmic transformation of the confirmed number of deaths for each country, ${ }^{14}$ we test for a break in trend. The results are reported in Table 1.

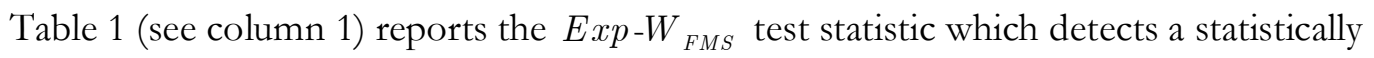
significant break in the trend for 19 out of 32 countries. The test results can be used to separate the countries into two distinct groups. The first group includes countries with no significant break in the trend of deaths while the second group consists of countries with a significant break. Therefore, the first group includes 13 countries $^{15}$ and the second group 19 countries. $^{16}$ For the latter group of countries, the Perron and Yabu (2009a) test identifies endogenously the break date $\left(t^{*}\right)$ at which the structural change in trend takes place (see column 2 of Table 1). Unsurprisingly, the date of the break occurs much earlier in China (the origin of the virus). The date of the break in Italy precedes the ones in Spain, France, the US, Germany and the UK. ${ }^{17}$ For countries like South Korea or Greece, we do not detect a trend in deaths; these are countries that have reported deaths of a similar magnitude on daily basis for the investigated sample.

Once the significant break date $t^{*}$ has been identified, we proceed by estimating the coefficient of trend component on the series through the method of Perron and Yabu (2009b). For the first group of countries, the slope estimation $\left(\hat{b}_{1}\right)$ takes place for the entire $\operatorname{ETS} S_{i}$ (see column 3 of Table 1), while for the second group of countries, the slope estimation $\left(\hat{b}_{1}^{\text {before }}\right)$ is performed from $t^{\oplus}$ (i.e. the start of $E T S_{i}$ ) up to the identified break date $t^{*}$ (see column 4 of Table 1). Thus, for both groups of countries, we obtain estimates for the average growth rate of deaths (along with their statistical significance) without allowing the identified structural

\footnotetext{
${ }^{13}$ In the case of Italy, for instance, the ETS spans from 27 February 2020 to 30 April 2020 (64 observations).

${ }^{14}$ In this case, the estimated coefficients (slope) represent the average growth rate of deaths.

${ }_{15}$ Argentina, Austria, Chile, Denmark, Egypt, Greece, Israel, Japan, South Korea, Malaysia, Norway, Panama and Saudi Arabia.

16 Belgium, Brazil, Canada, China, France, Germany, Indonesia, Iran, Ireland, Italy, the Netherlands, Philippines, Portugal, Spain, Sweden, Switzerland, Turkey, UK and US.

${ }_{17}$ For the UK, the structural break in the trend of deaths comes later than for other European countries including Italy, France, Spain and the Netherlands. Richard Horton (Editor of medical journal The Lancet) has been very critical of the UK's response to the crisis. For instance, Horton told the Science Select Committee of UK MPs in late March 2020 that the government's scientific advisers failed to take into account early warnings of the seriousness of the epidemic in China; see: https://cutt.ly/YyqHwA4.
} 
change in the trend to affect the magnitude of the coefficients. Notice, from column 4 of Table 1 that, among those 19 countries with a break in the trend of deaths, Spain records the highest average growth rate of deaths (that is, $30.6 \%$ per day) followed by the US (that is, $23.4 \%$ per day). After the break, the same 19 countries experience an average growth rate of deaths, which either slows down significantly or turns negative.

Table 1. Trend break test (Perron and Yabu, 2009a) and slope estimates (Perron and Yabu, 2009b).

\begin{tabular}{|c|c|c|c|c|c|c|}
\hline \multirow{3}{*}{ Country } & \multicolumn{6}{|c|}{ Column number } \\
\hline & (1) & (2) & (3) & (4) & (5) & (6) \\
\hline & $E x p-W_{F M S}$ & $t^{*}$ & $\hat{b}_{1}$ & $\hat{b}_{1}^{\text {before }}$ & $\hat{b}_{1}^{a f t e r}$ & $\hat{b}_{1}^{\text {after }}-\hat{b}_{1}^{\text {before }}$ \\
\hline Argentina & 0.965 & & 0.021 & - & - & - \\
\hline Austria & 0.229 & & 0.008 & - & - & - \\
\hline Belgium & $16.372^{* * *}$ & 03-Apr-20 & - & $0.191 * * *$ & $-0.060 *$ & -0.250 \\
\hline Brazil & $12.659 * * *$ & 04-Apr-20 & - & $0.174 * * *$ & $0.069 * * *$ & -0.105 \\
\hline Canada & $37.402^{* * *}$ & 09-Apr-20 & - & $0.182^{* * *}$ & 0.048 & -0.134 \\
\hline Chile & 0.235 & & 0.023 & - & - & - \\
\hline China & $126.144^{* * *}$ & 12-Feb-20 & - & $0.145^{* * *}$ & $-0.082^{* * *}$ & -0.227 \\
\hline Denmark & 0.380 & - & -0.005 & - & - & - \\
\hline Egypt & 0.221 & - & $0.047 * * *$ & - & - & - \\
\hline France & $181.331^{* * *}$ & 30-Mar-20 & - & $0.198^{* * *}$ & $-0.025^{* * *}$ & -0.223 \\
\hline Germany & $68.894 * * *$ & 03-Apr-20 & - & $0.203^{* * *}$ & 0.007 & -0.197 \\
\hline Greece & 0.670 & - & $-0.022^{* *}$ & - & - & - \\
\hline Indonesia & $2.654 * *$ & 15-Apr-20 & - & $0.044^{*}$ & -0.032 & -0.075 \\
\hline Iran & $91.594 * * *$ & 18-Mar-20 & - & $0.163^{* * *}$ & -0.012 & -0.175 \\
\hline Ireland & $13.458^{* * *}$ & 15-Apr-20 & - & $0.074 * * *$ & $-0.031 *$ & -0.105 \\
\hline Israel & 0.201 & - & -0.014 & - & - & - \\
\hline Italy & $54.001 * * *$ & 19-Mar-20 & - & $0.212^{* * *}$ & -0.010 & -0.221 \\
\hline Japan & 0.714 & - & 0.030 & - & - & - \\
\hline South Korea & 0.573 & - & -0.001 & - & - & - \\
\hline Malaysia & 0.263 & - & $-0.027 * * *$ & - & - & - \\
\hline The Netherlands & $13.139 * * *$ & 27-Mar-20 & - & $0.216^{* * *}$ & $-0.031 *$ & -0.247 \\
\hline Norway & 0.238 & - & -0.006 & - & - & - \\
\hline Panama & 0.306 & - & -0.028 & - & - & - \\
\hline Philippines & $2.987^{* *}$ & 12-Apr-20 & - & $0.081^{* * *}$ & -0.035 & -0.116 \\
\hline Portugal & $17.351 * * *$ & 05-Apr-20 & - & $0.105^{* * *}$ & $-0.019 * * *$ & -0.124 \\
\hline Saudi Arabia & 0.261 & - & 0.007 & - & - & - \\
\hline Spain & $374.278^{* * *}$ & 25-Mar-20 & - & $0.306^{* * *}$ & $-0.028^{* * *}$ & -0.334 \\
\hline Sweden & $13.951 * * *$ & 06-Apr-20 & - & $0.149 * * *$ & -0.049 & -0.198 \\
\hline Switzerland & $100.086^{* * *}$ & 01-Apr-20 & - & $0.121^{* * *}$ & $-0.052 * * *$ & -0.173 \\
\hline Turkey & $11.668^{* * *}$ & 05-Apr-20 & - & $0.185^{* * *}$ & 0.006 & -0.179 \\
\hline UK & $23.850 * * *$ & 03-Apr-20 & - & $0.216^{* * *}$ & 0.002 & -0.215 \\
\hline US & $22.376^{* * *}$ & 02-Apr-20 & - & $0.234^{* * *}$ & $0.024 * *$ & -0.210 \\
\hline
\end{tabular}

Notes: For column $1, * * *, * *$ and $*$ denote a statistically significant break in trend at the $0.01,0.05$, and 0.10 level, respectively. For columns 3, 4, and 5,***,** and * refer to the statistical significance of the estimated slope.

Focusing on the significance of the slope estimates (see columns 3 and 4 of Table 1) for all countries, we move on to investigate within a binary choice framework the validity of 
the first hypothesis. Thus, for each country $i(i=1, \ldots, 32)$ we define the dichotomous variable $D_{i}$ which takes the value of one (1) if a non-significant slope coeffient is estimated and zero (0) if the coefficient is significant. ${ }^{18}$ In this case, $D_{i}$ takes the value of 1 for 13 countries and the value of 0 for 19 countries.

Moreover, for each observation $t$ of the sample $T$, we define the strength $\left(S^{t}\right)$ of the overall policies (implemented to control the spread of COVID-19) as the average value of the OxCGRT index over the period $t-1$ to $t-14 \cdot{ }^{19}$ We further define the concept of early stage policies at time $t$, when $t$ is less than or equal to $t^{\oplus}\left(t \leq t^{\oplus}\right)$. Thus, for each country $i$, we build the early stage strength of the overall policies at time $t^{\oplus}$ (start of $E T S_{i}$ ), denoted by $S_{i}^{t^{\oplus}}$. Hence, the first hypothesis is examined by the following simple probit specification:

$$
D_{i}=\vartheta_{0}+\vartheta_{1} S_{i}^{t^{\oplus}}+u_{i},
$$

where $\vartheta_{0}$ and $\vartheta_{1}$ are parameters to be estimated and $u_{i}$ is the error term assuming the usual properties (an i.i.d. normally distributed process). In this specification, a statistically significant and positive value for the coefficient $\vartheta_{1}$ would indicate that the strength of the policy measures at an early stage $\left(S_{i}^{t^{\oplus}}\right)$ is related positively to the probability of attaining an insignificant slope for the series of deaths. The estimates of equation $(10)^{20}$ are shown in Table 2 below.

In terms of the first hypothesis (that is, speed is of the essence), the relevant coefficient $\vartheta_{1}$ is positive and significant at the 0.01 significance level. This finding implies that the higher the strength of the policy measures at an early stage, the higher the probability of attaining an insignificant trend slope for the observed deaths. In more detail, the associated marginal effect to the estimated coefficient (that is, 0.011) suggests that for every unit increase in the strength of the OxCGRT index, the probability of attaining an insignificant trend component on the death series increases by $1.1 \%$.

\footnotetext{
${ }_{18}$ Notice that the slope estimates for the countries with a break are all positive and statistically significant.

19 The strength is calculated for the observations that belong to the $[15, T]$ interval.

20 The motivation for using equation (10) relates to the epidemiological model reported in section 3. In particular, if, at the early stage of an outbreak, anti-contagion policies are implemented, then the transmission rate parameter $(\beta)$ as well as the growth rate of infections and the growth rate of deaths should all be influenced negatively. Hence, we expect for countries that have implemented harsh anti-contagion policies, the transmission rate to decrease in magnitude and, therefore, the slope of deaths (average growth rate) not to be statistically different from zero. On the other hand, consider the case where such policies are not implemented and/or stringency is low. Then, the transmission rate will increase in magnitude and, therefore, the slope of deaths (average growth rate) will be positive and statistically different from zero.
} 
Table 2. Probit regression results for $D_{i}=\vartheta_{0}+\vartheta_{1} S_{i}^{t^{\oplus}}+u_{i}$ (Hypothesis 1)

\begin{tabular}{cccccc}
\hline Coefficient & Estimate & $\begin{array}{c}\text { Marginal } \\
\text { effect }\end{array}$ & $\begin{array}{c}\text { Coefficient } \\
\text { robust s.e. }\end{array}$ & $\begin{array}{c}\text { Coefficient } \\
p \text {-value }\end{array}$ & $\begin{array}{c}\text { Coefficient } \\
95 \% \text { Conf. Interval }\end{array}$ \\
\hline$\vartheta_{0}$ & $-3.571 * * *$ & - & 0.868 & 0.000 & {$\left[\begin{array}{lll}-5.272, & -1.871\end{array}\right]$} \\
$\vartheta_{1}$ & $0.072 * * *$ & $0.012^{* * *}$ & 0.021 & 0.000 & {$\left[\begin{array}{lll}0.032, & 0.114\end{array}\right]$} \\
\hline \multicolumn{7}{c}{ Statistics and Diagnostics } \\
\hline $\begin{array}{l}\text { McFadden R-squared } \\
\text { Log likelihood }\end{array}$ & 0.572 & HL Stat. $p$-value \\
\hline
\end{tabular}

Notes: The symbol *** implies that the estimate is significant at the 0.01 significance level. The specification is estimated by the Maximum Likelihood estimation approach using robust standard errors (s.e.). The Hosmer and Lemeshow (1989) HL statistic fails to reject the null hypothesis that the observed and expected proportions are the same across all constructed groups, implying a good model fit. Finally, the LM test for heteroscedasticity as illustrated in Davidson and MacKinnon (2004) fails to reject the null hypothesis of no heteroscedasticity.

Figure 4 illustrates, for different strength levels of the OxCGRT index at time $t^{\oplus}$, the predicted probability (along with the 95\% confidence interval) of attaining an insignificant trend component.

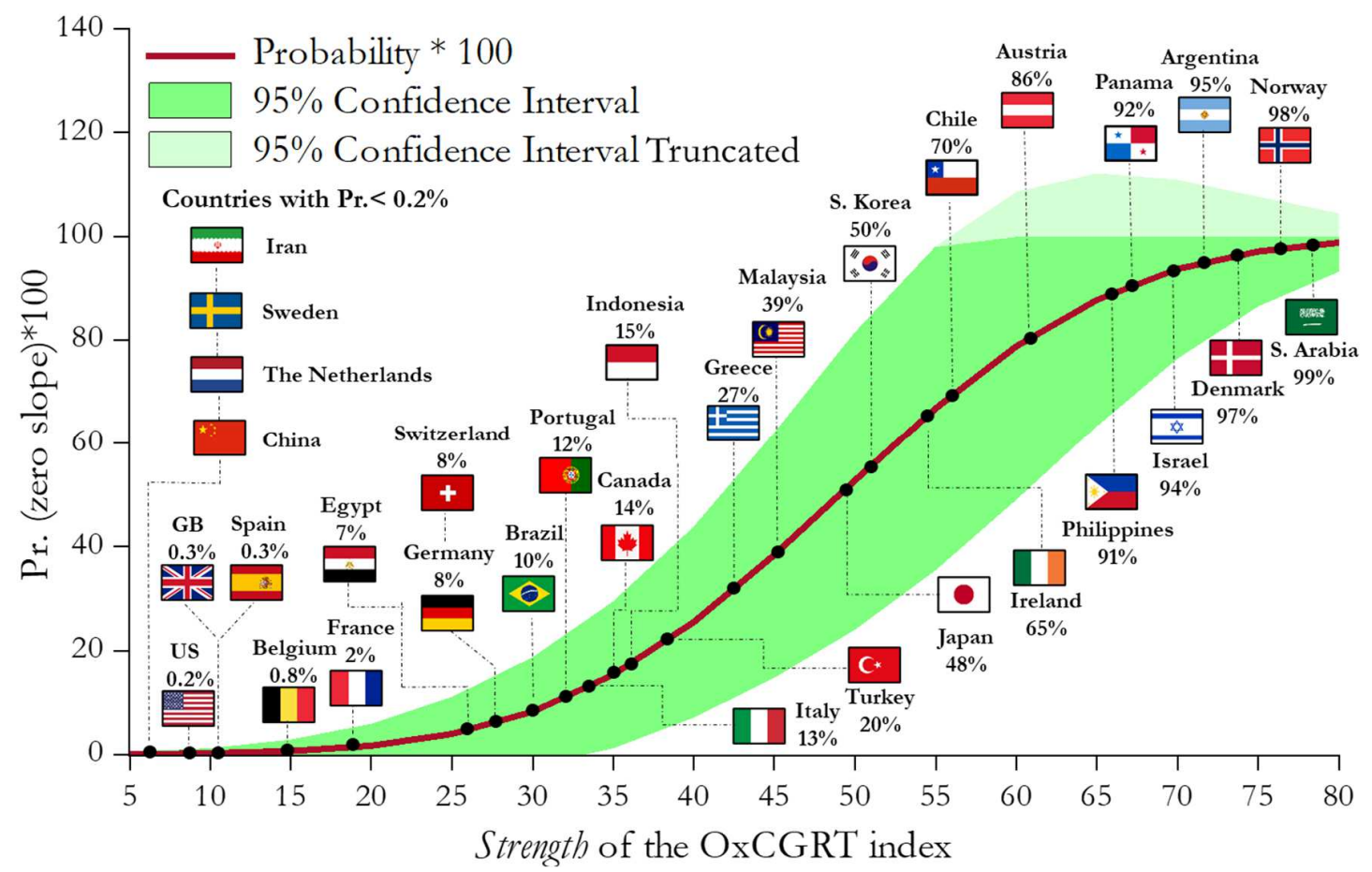

Figure 4. OxCGRT index strength at $t^{\oplus}$ and predicted probability of an insignificant trend 
From Figure 4, policy measures taken at an early stage appear to be more effective when their strength is greater. For instance, if the strength of measures is above 65 units, the predicted probability for attaining a zero slope exceeds $85 \%$, whereas if the strength of measures is 35 units, the respective probability is just $15 \%$. We have super-imposed in Figure 4 all countries of our sample. Given, for instance, the strength of measures in the U.K., France and Italy, their predicted probabilities are only $0.3 \%, 2 \%$ and $13 \%$, respectively. For South Korea, the predicted probability quadruples to $50 \%$ given the country's greater strength of measures at an early stage. Overall, our findings offer support to the validity of the first hypothesis.

To examine the validity of the second hypothesis (that is, stringency matters) our focus turns to those 20 countries with a statistically significant positive trend coefficient (see columns 3 and 4 of Table 1). ${ }^{21}$ To do so, we construct the $C_{j}^{+}$variable by assigning to each country $j(j=1, \ldots, 20)$ the respective slope $\left(\hat{b}_{1}\right.$ or $\left.\hat{b}_{1}^{b e f o r e}\right)$, only if this slope is positive and statistically significant. Thus, the second hypothesis is examined by the following specification:

$$
C_{j}^{+}=\mu_{0}+\mu_{1} S_{j}^{t^{\oplus}}+u_{j},
$$

where $\mu_{0}$ and $\mu_{1}$ are parameters to be estimated and $u_{j}$ is the error term. A negative value for the coefficient $\mu_{1}$ would indicate that the higher the strength of the policies at an early stage, the lower the growth rate of deaths for the subsequent period. The estimates of equation $(11)^{22}$ are reported in Table 3.

Table 3. Regression results for $C_{j}^{+}=\mu_{0}+\mu_{1} S_{j}^{t \oplus}+u_{j}$ (Hypothesis 2)

\begin{tabular}{cccccc}
\hline Coefficient & Estimate & Newey-West s.e. & $t$-statistic & $p$-value & $95 \%$ Conf. Interval \\
\hline$\mu_{0}$ & $0.216^{* * *}$ & 0.025 & 8.60 & 0.000 & {$\left[\begin{array}{lll}0.171, & 0.261\end{array}\right]$} \\
$\mu_{1}$ & $-0.002^{* * *}$ & 0.001 & -3.68 & 0.001 & {$\left[\begin{array}{lll}-0.003, & -0.001\end{array}\right]$} \\
\hline \multicolumn{7}{c}{ Statistics and Diagnostics } \\
\hline R-squared & 0.295 & B.G. Chi-squared $p$-value & 0.501 \\
White Chi-squared $p$-value & 0.588 & J.B. normality $p$-value & 0.870 \\
\hline
\end{tabular}

Notes: The symbol *** implies that the estimate is significant at the 0.01 significance level. The specification is estimated by OLS using the Newey and West general covariance estimator for the reported standard errors (s.e.). The $p$-value associated to the White's test for heteroscedasticity implies no heteroscedasticity. Similarly, the $p$-value of the Breusch and Godfrey (B.G.) test for serial correlation suggests no serial correlation. Finally, the $p$-value for the Jarque-Bera test provides evidence in failing to reject the null hypothesis, implying normality for the error term. The diagnostic tests suggest no evidence of specification error.

${ }^{21}$ Belgium, Brazil, Canada, China, Egypt, France, Germany, Indonesia, Iran, Ireland, Italy, the Netherlands, Philippines, Portugal, Spain, Sweden, Switzerland, Turkey, the UK and the US.

22 The motivation for this specification links directly to equation (6) of section 3. 
With reference to the second hypothesis, the relevant coefficient $\mu_{1}$ is negative and significant. The estimated coefficient (-0.002) suggests that for every unit increase in the strength of the index at an early stage, the slope of the trend component reduces by $0.2 \%$. In the case of the UK, given the strength of the country's measures at $t^{\oplus}$, the predicted daily average growth rate of deaths is $19.4 \%$ (that is, $0.216-0.002 * 11$; this compares with an actual value of $21.6 \%$ from column 4 of Table 1). For Italy, the respective prediction is $14.8 \%$ (this compares with an actual value of $21.2 \%$ from column 4 of Table 1). Overall, our findings provide support to the validity of the second hypothesis.

For the third hypothesis (that is, speed of adjustment matters), attention is paid to those 19 countries with a significant break in trend (see column 1 of Table 1). We estimate for each country $m(m=1, \ldots, 19)$ the trend slope after $\left(\hat{b}_{1, m}^{\text {after }}\right)$ the identified break date through the method of Perron and Yabu (2009b). Given our estimates for $\hat{b}_{1, m}^{a f t e r}$ (see column 5 of Table 1), and $\hat{b}_{1, m}^{\text {before }}$ (see column 4 of Table 1), we construct the difference $\hat{b}_{1, m}^{\text {after }}-\hat{b}_{1, m}^{\text {before }}$ (see column 6 of Table 1). Moreover, we calculate for each country $m$ the strength of its policies at $t^{*}$ denoted by $S_{m}^{t^{*}}$. Hence, the difference of $S_{m}^{t^{*}}-S_{m}^{t^{\oplus}}$ can be seen as the adjustment in the strength of the conducted policies over the time distance between $t^{\oplus}$ and $t^{*}$ in response to the COVID-19 outbreak. Thus, the final hypothesis is explored through the following specification:

$$
\left(\hat{b}_{1, m}^{\text {after }}-\hat{b}_{1, m}^{\text {before }}\right)_{m}=\gamma_{0}+\gamma_{1}\left(S_{m}^{t^{*}}-S_{m}^{t^{\oplus}}\right)_{m}+u_{m},
$$

where $\gamma_{0}$ and $\gamma_{1}$ are parameters and $u_{m}$ is the error term. A negative value for $\gamma_{1}$ would indicate an inverse relationship between the adjustment in the strength of policies (over the time distance from $t^{\oplus}$ to $t^{*}$ ), and the change in the slopes before and after $t^{*}$. The estimates of equation $(12)^{23}$ are reported in Table 4. With reference to the third hypothesis (speed of adjustment matters), the $\gamma_{1}$ coefficient is negative and significant. Consequently, an increase in the strength of measures (between $t^{\oplus}$ and $t^{*}$ ), leads to a decrease in the average growth rate of deaths after $t^{*}$ (compared to the respective growth rate before $t^{*}$ ).

${ }^{23}$ The motivation for this specification links directly to equation (6) (of section 3) in first differences. 
Table 4. Regression results for $\left(\hat{b}_{1, m}^{\text {after }}-\hat{b}_{1, m}^{\text {before }}\right)_{m}=\gamma_{0}+\gamma_{1}\left(S_{m}^{t^{*}}-S_{m}^{t \oplus}\right)_{m}+u_{m}$ (Hypothesis 3)

\begin{tabular}{ccccccc}
\hline Coefficient & Estimate & N.W. s.e. & $t$-statistic & $p$-value & $95 \%$ Conf. Interval \\
\hline$\gamma_{0}$ & -0.039 & 0.049 & -0.803 & 0.434 & {$\left[\begin{array}{lll}-0.134, & 0.056\end{array}\right]$} \\
$\gamma_{1}$ & $-0.003^{* * *}$ & 0.001 & -3.544 & 0.002 & {$\left[\begin{array}{lll}-0.005, & -0.001\end{array}\right]$} \\
\hline \multicolumn{7}{c}{ Statistics and Diagnostics } \\
\hline R-squared & 0.488 & B.G. Chi-squared $p$-value & 0.708 \\
White Chi-squared $p$-value & 0.969 & J.B. normality $p$-value & 0.592 \\
\hline
\end{tabular}

Notes: See the respective notes in Table 3. Overall, the diagnostic tests of the estimated equation suggest no evidence of specification error.

The estimated coefficient $(-0.003)$ suggests that for every unit increase in the strength of the index between $t^{\oplus}$ and $t^{*}$, the slope in the period after $t^{*}$ reduces by $0.3 \%$ (compared to the respective slope for the period before $t^{*}$ ). In the case of the UK, for instance, where the change in the strength of measures is 58.4 units, the predicted change in the daily growth rate of deaths is $-21.4 \%$ (that is, $-0.039-0.003 * 58.4$; this compares with an actual value of $21.5 \%$ from column 6 of Table 1). The respective prediction for Italy is $-17.9 \%$ (this compares with an actual value of $-22.1 \%$ from column 6 of Table 1 ).

Overall, by exploiting the trend signals of the death series for 32 countries and relying on the stringency of the conducted policies, we find that government interventions are effective in slowing down or reversing the growth rate of deaths. The studies of Flaxman et al. (2020) and Hsiang et al. (2020) reach qualitatively similar findings by implementing different methodological approaches. Flaxman et al. (2020) fit a counterfactual epidemiological model to 11 European countries to find that strong anti-contagion policy measures have a large impact on reducing transmission. Hsiang et al. (2020) fit a reduced form econometric model to six countries to find that strong anti-contagion policies have significantly slowed the growth rate of infections.

\section{Robustness checks}

Published COVID-19 data (registered infections, hospitalizations, deaths) are subject to all kinds of under-reporting. Raftery et al. (2020) discuss in detail specific limitations and cautions regarding COVID-19 data (cases, hospitalizations, emergency department visits, deaths, excess deaths) and what the implications are for decision making. Indeed, decision makers can make better choices when they have better understanding of the strengths and limitations of these data. Raftery et al. (2020) note that the number of confirmed COVID-19 cases is "likely 
to be a substantial underestimate of the prevalence of the disease in a population given that most people with COVID-19 are asymptomatic, and even among those who are symptomatic, not all are tested." They also note that COVID-19 deaths "are affected by the accuracy of cause-of-death determinations and reflect the state of the outbreak several weeks previously because of the long course of COVID-19 infection." They view excess deaths as the best mortality indicator of the COVID-19 outbreak, but also note that because of the possibility of death misclassification, excess deaths represent a mix of confirmed COVID-19 deaths and deaths from other causes.

Thus, the presence of measurement errors raises the issue of whether one can be sufficiently confident that the empirical results reported above are reliable to inform decision making. Since our empirical setting focuses on the inherent trend signal of the deaths attributed to COVID-19, our analysis could be potentially misleading if the employed dataset fails to reveal the true trajectory of the trend. To address this concern, and following Raftery et al. (2020) who note that "compared with the other data reviewed here, excess deaths are the best indicator of the mortality impacts of the pandemic", we look at the excess mortality data compiled by The Financial Times (FT). ${ }^{24}$

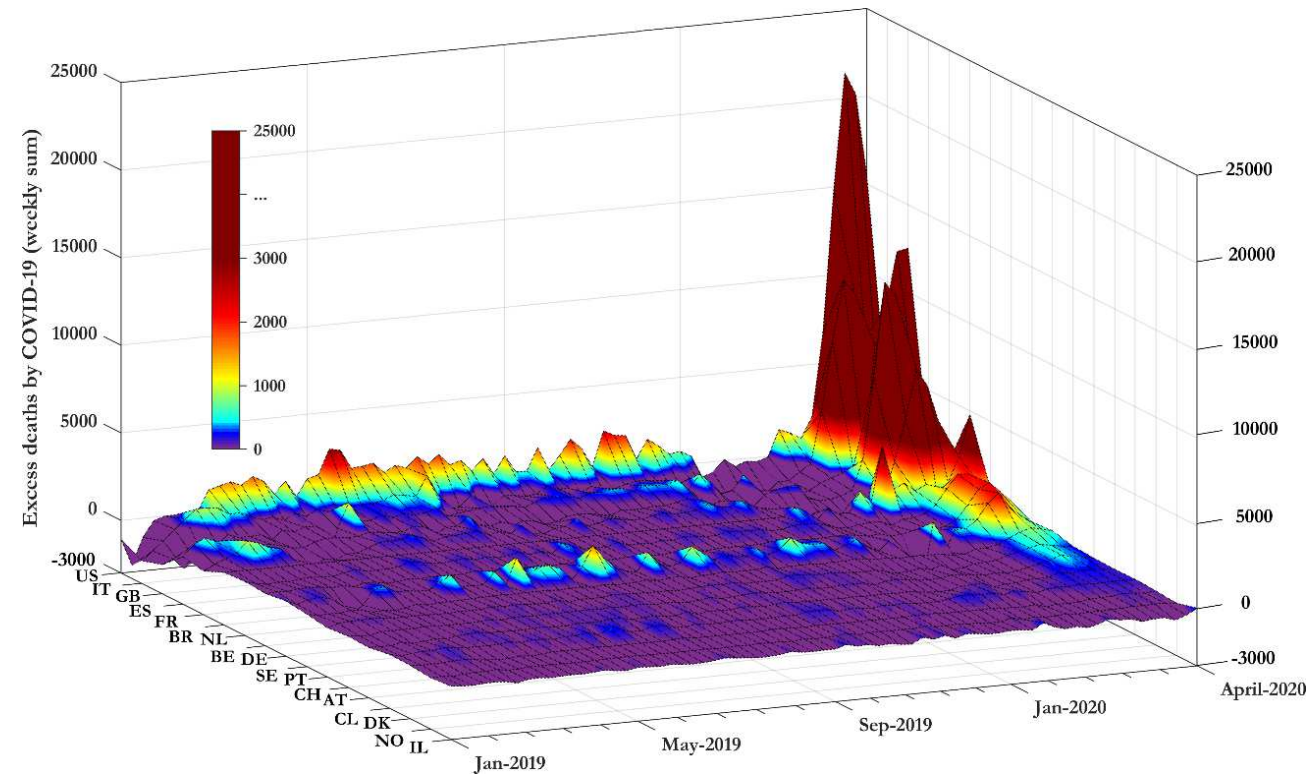

Figure 5. Excess mortality attributed to all causes of death by country

24 The dataset is discussed at https://www.ft.com/content/a26fbf7e-48f8-11ea-aeb3-955839e06441 and provided at https://github.com/Financial-Times/coronavirus-excess-mortality-data. For presentation purposes, missing observations are interpolated through the quadratic-match average method. Again, for presentation purposes, excess deaths are plotted since 2019. Doing so allow us to see how excess mortality has evolved prior to and during the COVID-19 outbreak. 
The FT dataset provides weekly data on excess mortality for a number of countries. ${ }^{25}$ Excess mortality refers to the difference between the observed number of deaths (attributed to all causes) in the weeks of January 2019 to April 2020 and the median value for the same periods between 2015 and 2019. Excess mortality data are presented in Figure 5. We focus on 17 countries that are common to the FT excess mortality dataset and our sample; 12 of these countries exhibit positive excess mortality from mid-March 2020 onwards. Although not all of these excess deaths are necessarily attributable to the COVID-19 disease, we may argue with reasonable confidence that excess deaths adequately capture the trend signal of the true COVID-19 deaths. ${ }^{26}$ To validate our analysis, we calculate the correlation coefficient between the number of COVID-19 deaths reported by the ECDC dataset and the excess mortality figures reported by the FT dataset. The correlation coefficients for each country are reported in Figure $6{ }^{27}$

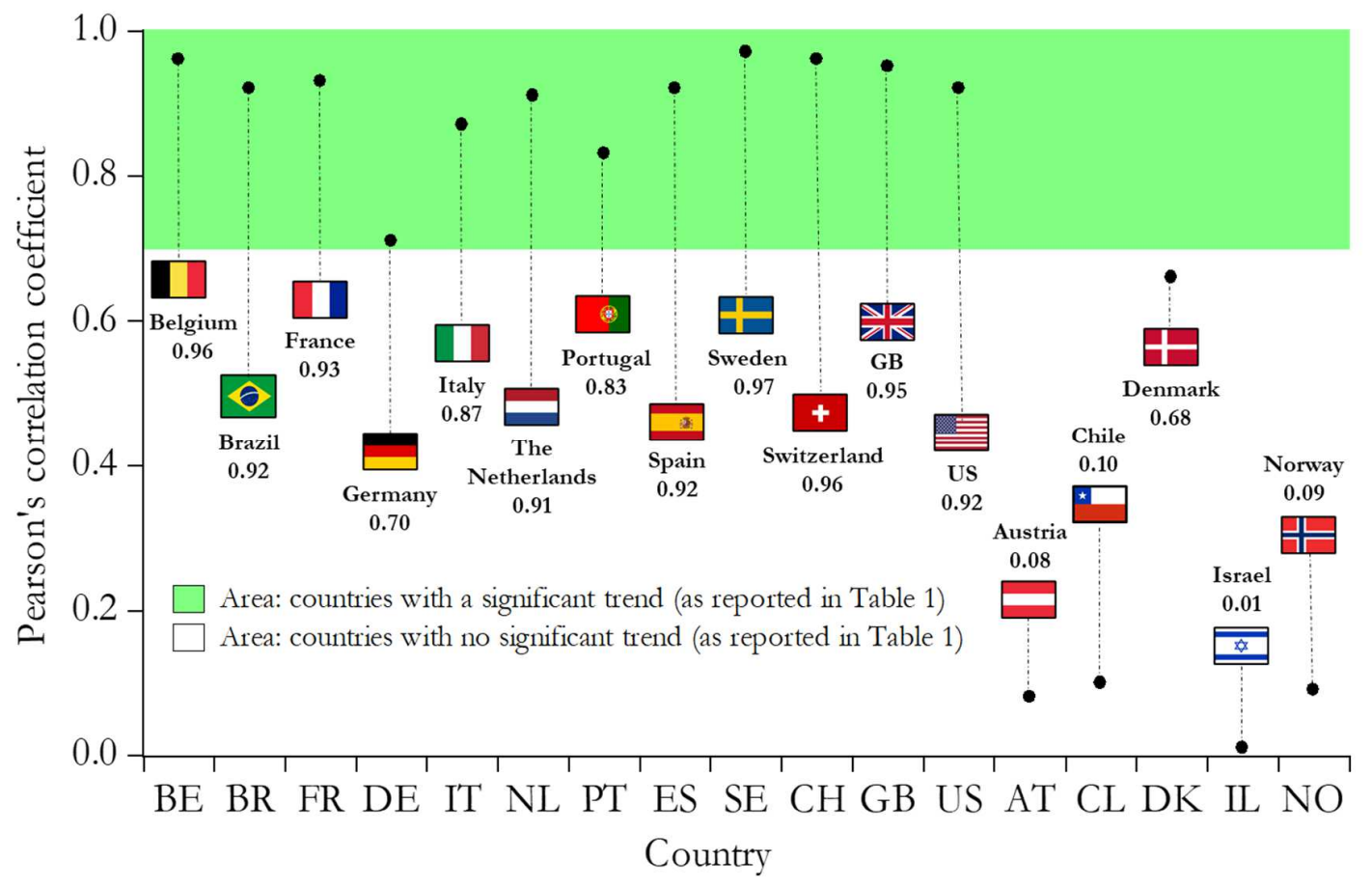

Figure 6. Correlation coefficient between COVID-19 deaths and excess mortality

\footnotetext{
25 The data for Indonesia and Turkey refer only to Istanbul and Jakarta, respectively, and thus are excluded. 26 The literature on excess mortality is currently emerging. For instance, Vandoros (2020; see also references therein) hints to the possibility that some people might have died from COVID-19 without being diagnosed. He also points to spillover effects on other causes such as patients postponing their hospital appointments because of fear of contacting the virus in hospitals.

${ }^{27}$ For each country, the sample used to estimate the correlation coefficient extends from the time where the first death is observed to 30 April 2020.
} 
We can reasonably expect that COVID-19 deaths from the ECDC dataset would exhibit a high degree of linear association with excess mortality FT data for all countries with a significant positive trend, as reported in Table 1. These are 12 countries in total. Conversely, the COVID-19 deaths from the ECDC dataset would arguably exhibit a lower degree of linear association with the excess mortality FT data, for all countries with an insignificant trend (as reported in Table 1). These are 5 countries in total. From Figure 6, the correlation coefficients for the 12 countries (exhibiting a significant trend) range between 0.70 and 0.97 (the average correlation coefficient value for these 12 countries is 0.90$)$. The correlation coefficients for the remaining 5 countries (exhibiting an insignificant trend) are considerably lower (the average correlation coefficient value for these 5 countries is 0.19$)$. Given these findings, we argue that despite the existence of errors in the measurement of the reported deaths of the ECDC dataset, the dataset is still capable of correctly signaling the true trajectory of the trend. Therefore, our analysis is sufficiently reliable to inform decision making.

We move on and turn our attention to school closures. Rather than using the aggregate stringency index of government interventions, we repeat our analysis by focusing on the 'school closures' component of the OxCGRT index. Consequently, we look at the strength of the school closure policy defined as the average value of the 'school closures' sub-index for the preceding 14-days of the time points of interest (that is; $t^{\oplus}$ and $t^{*}$ ). School closures have been the focus of media attention. ${ }^{28}$ The Guardian, for instance, notes that there is very little evidence that school closures are effective in combating COVID-19. Viner et al. (2020) provide a comprehensive review (see also references therein) of the impact of school closures during coronavirus outbreaks around the world. They make the point that "the evidence to support national closure of schools to combat COVID-19 is very weak and data from influenza outbreaks suggest that school closures could have relatively small effects on a virus with COVID-19's high transmissibility and apparent low clinical effect on school children" (Viner et al. 2020; pp. 402-403). Viner et al. (2020) also flag the economic costs of school closures. Indeed, from previous virus outbreaks, school closure costs are estimated between $0.2 \%$ and $1 \%$ of UK national gross domestic product per annum for school closures of 12-13 weeks and up to 3\% of GDP for an 8-week school closure in the US. Ferguson et al. (2020) use an

${ }^{28}$ See: https://cutt.ly/tylYHhC. 
epidemiological model to find that school closures alone would prevent only $2-4 \%$ of deaths, much less than other social distancing interventions.

Using the school closures sub-index in our specifications instead of the aggregate stringecy index, we estimate $\vartheta_{1}$ at 0.034 in equation (10), $\mu_{1}$ at -0.001 in equation (11) and $\gamma_{1}$ at -0.001 in equation (12). These are statistically significant at the 0.01 level but lower in magnitude than the estimates for the aggregate stringecy index. Using school closures, the associated marginal effect to the estimated slope coefficient in equation (10) is 0.007 . This suggests that for every unit increase in the strength of school closures sub-index at an early stage, the probability of attaining an insignificant trend component on the death series increases by $0.7 \%$. Using school closures, the estimated slope coefficient (-0.001) in equation (11) suggests that for every unit increase in the strength of the school closures sub-index at an early stage, the slope of the trend component on the death series reduces by $0.1 \%$. Using school closures in equation (12), the estimated coefficient (-0.001) suggests that for every unit increase in the strength of the school closures sub-index between the time points $t^{\oplus}$ and $t^{*}$, the slope in the period after $t^{*}$ reduces by $0.1 \%$ compared to the respective slope for the period before $t^{*}$.

Therefore, our results suggest that school closures have an impact in driving COVID19 deaths down on their own but, unsurprisingly, their impact is less powerful compared to the case where a number of policy interventions are combined together. Finally, relying on the findings of Chudik et al. (2020), rather than using a 14-day window to calculate the strength of the conducted policies, we have repeated the entire analysis adopting a 21-day window. The results (available on request) are qualitatively similar to those reported here.

\section{Conclusions}

COVID-19 developments dominate the news not only because of the challenging social costs and growing numbers of lives lost, but also the economic costs resulting from closures and social distancing measures. This paper assesses the quantitative impact of government interventions on COVID-19 deaths. Using daily data for 32 countries and relying on the stringency of the conducted policies, we find that the greater the strength of government interventions at an early stage, the more effective these are in slowing down or reversing the growth rate of deaths. School closures, on their own, have a significant impact, but they are less powerful in driving deaths down than are combinations of government interventions. 
Overall, government decisiveness in taking early action is paramount to control the virus. Forman et al. (2020) also flag the importance of data, information, models, and the processes by which policy-making decisions are made to be available for scrutiny in order to enhance trust and strengthen the response to the pandemic. We hope that governments can use some of the results of this paper to respond to future COVID-19 outbreaks or other pandemics. This is important not least because there is a possibility of further waves of COVID-19 infections and deaths as governments progressively relax their interventions. In fact, a sustainable exit strategy may not be very straightforward. As noted by Anderson et al. (2020), the implementation of social distancing measures has been politically challenging but technically simple. On the other hand, easing social distancing measures will most likely involve a process of trial and error, especially if there is evidence of further COVID-19 outbreaks emerging.

\section{References}

Amaro, J.E., J. Dudouet and J.N. Orce (2020). Global Analysis of the COVID-19 Pandemic Using Simple Epidemiological Models, https://arxiv.org/abs/2005.06742.

Anderson, M., M. Mckee and E. Mossialos (2020). Developing a Sustainable Exit Strategy for COVID-19: Health, Economic and Public Policy Implications. Journal of the Royal Society of Medicine, 113, 176-178.

Barro, R.J., J.F. Ursua and J. Weng (2020). The Coronavirus and the Great Influenza Epidemic - Lessons from the "Spanish Flu" for the Coronavirus's Potential Effects on Mortality and Economic Activity. CESifo Working Paper No. 8166.

Basu, P., C. Bell and T.H. Edwards (2020). COVID Social Distancing and the Poor: An Analysis of the Evidence for England. Unpublished Working Paper (21 August 2020).

Chen, X. and Z. Qiu (2020). Scenario analysis of non-pharmaceutical interventions on global Covid-19 transmissions. Covid Economics, Issue 7: April 20 2020, 46-67.

Chudik, A., M.H. Pesaran and A. Rebucci (2020). Voluntary and Mandatory Social Distancing: Evidence on COVID-19 Exposure Rates from Chinese Provinces and Selected Countries. CESifo Working Paper No. 8243.

Cowling, B.J., S.T. Ali, T.W.Y. Ng, T.K. Tsang, J.C.M. Li, M.W. Fong, Q. Liao, M.Y.W. Kwan, S.L. Lee, S.S. Chiu, J.T. Wu, P. Wu and G.M. Leung (2020). Impact assessment of non- 
pharmaceutical interventions against coronavirus disease 2019 and influenza in Hong Kong: an observational study. The Lancet Public Health, April 17 2020, pp. 1-10.

Davidson, R. and J.G. MacKinnon (2004). Econometric Theory and Methods. Oxford University Press, Oxford.

Ferguson N.M., D., Laydon, G. Nedjati-Gilani, N. Imai, K. Ainslie, M. Baguelin, S. Bhatia, A. Boonyasiri, Z. Cucunubá, G. Cuomo-Dannenburg, A. Dighe, I. Dorigatti, H. Fu, K. Gaythorpe, W. Green, A. Hamlet, W. Hinsley, L.C. Okell, S. van Elsland, H. Thompson, R. Verity, E. Volz, H. Wang, Y. Wang, P.G.T. Walker, C. Walters, P. Winskill, C. Whittaker, C.A. Donnelly, S. Riley and A.C. Ghani (2020). Report 9: impact of nonpharmaceutical interventions (NPIs) to reduce COVID-19 mortality and healthcare demand. London: Imperial College, 16 March 2020. Available from: https://www.imperial.ac.uk/media/imperial-college/medicine/sph/ide/gidafellowships/Imperial-College-COVID19-NPI-modelling-16-03-2020.pdf

Flaxman, S., S. Mishra, A. Gandy, H.J.T. Unwin, T.A. Mellan, H. Coupland, C. Whittaker, H. Zhu, T. Berah, J.W. Eaton, M. Monod, Imperial College COVID-19 Response Team, A.C. Ghani, C.A. Donnelly, S.M. Riley, M.A.C. Vollmer, N.M. Ferguson, L.C. Okell and S. Bhatt (2020). Estimating the effects of non-pharmaceutical interventions on COVID19 in Europe. Nature. https://doi.org/10.1038/s41586-020-2405-7.

Forman, R., R. Atun, M. McKee and E. Mossialos (2020). 12 Lessons Learned from the Management of the Coronavirus Pandemic. Health Policy, 124, 577-580.

Gibney, E. (2020). Whose coronavirus strategy worked best? Scientists hunt most effective policies. Nature 581, 15-16.

Hale, T., S. Webster, A., Petherick, T., Phillips and B., Kira (2020). Oxford COVID-19 Government Response Tracker. Blavatnik School of Government, University of Oxford. Data use policy: Creative Commons Attribution CC BY standard. Available from: https://www.bsg.ox.ac.uk/research/research-projects/coronavirus-governmentresponse-tracker.

Hartl, T., K. Wälde and E. Weber (2020a). Measuring the impact of the German public shutdown on the spread of Covid-19. Covid Economics, Issue 1: April 03 2020, 25-32.

Hartl, T., K. Wälde and E. Weber (2020b). Measuring the impact of the German public shutdown on the spread of COVID-19.VOX CEPR Policy Portal blog piece, 14 April 2020. Available from: Available from: https://voxeu.org/article/measuring-impactgerman-public-shutdown-spread-covid-19.

Hsiang, S., D. Allen, S. Annan-Phan, K. Bell, I. Bolliger, T. Chong, H. Druckenmiller, L.Y. Huang, A. Hultgren, E. Krasovich, P. Lau, J. Lee, E. Rolf, J. Tseng and T. Wu (2020). The effect of large-scale anti-contagion policies on the COVID-19 pandemic. Nature https://doi.org/10.1038/s41586-020-2404-8.

Jordà, O., S.R. Singh and A.M. Taylor (2020). Longer-run economic consequences of pandemics. Covid Economics, Issue 1: April 03 2020, pp 1-15. 
Lauer S., K.H. Grantz, BA, Qifang Bi, F.K. Jones, Q. Zheng, H.R. Meredith, A.S. Azman, N.G. Reich, J. Lessler (2020). The Incubation Period of Coronavirus Disease 2019 (COVID-19) From Publicly Reported Confirmed Cases: Estimation and Application. Annals of Internal Medicine, 172, 577-582.

Ma, J. (2020). Estimating epidemic exponential growth rate and basic reproduction number. Infectious Disease Modelling, 5, 129-141.

Manski, C.F. and F. Molinari (2020). Estimating the COVID-19 Infection Rate: Anatomy of an Inference Problem. Journal of Econometrics (article in press).

Perron, P. and T. Yabu (2009a). Testing for shifts in trend with an integrated or stationary noise component. Joumal of Business and Economics Statistics, 27, 369-396.

Perron, P. and T. Yabu (2009b). Estimating Deterministic Trends with an Integrated or Stationary Noise Component. Journal of Econometrics, 151, 56-69.

Raftery, A.E., J. Currie, M.T. Bassett and R. Groves (2020). Evaluating data types. A Guide for Decision Makers using Data to Understand the Extent and Spread of COVID-19. Societal Experts Action Network (SEAN), The National Academies of Sciences, Engineering, and Medicine, June 2020. Available from:

https://www.nap.edu/catalog/25826/evaluating-data-types-a-guide-for-decisionmakers-using-data.

Romano A., C. Sotis, G. Dominioni and S. Guidi (2020). The scale of COVID-19 graphs affects understanding, attitudes, and policy preferences. Health Economics, Forthcoming.

Roy, A. and W.A. Fuller (2001). Estimation for Autoregressive Processes with a Root Near One. Journal of Business and Economic Statistics, 19, 482-493.

Unkel, S., C.P. Farrington and P.H. Garthwaite (2012). Statistical Methods for the Prospective Detection of Infectious Disease Outbreaks: a Review. Journal of the Royal Statistical Society Series A, 175, Part 1, 49-82.

Vandoros, S. (2020). Excess mortality during the Covid-19 pandemic: Early evidence from England and Wales. Social Science \& Medicine, 258, Article 113101.

Viner, R.M., Russell, S.J., Croker, H., Packer, J., Ward, J., Stansfield, C., Mytton, O. Bonell, C. and R. Booy (2020). School closure and management practices during coronavirus outbreaks including COVID-19: a rapid systematic review. The Lancet Child \& Adolescent Health, 4, 397-404. 